\title{
COMPARATIVE STUDY OF LAPAROSCOPIC APPENDECTOMY VERSUS OPEN APPENDECTOMY AT BIRAT MEDICAL COLLEGE TEACHING HOSPITAL
}

\author{
Sanjaya Kumar Yadav ${ }^{1 *}$, Sabin Shrestha ${ }^{2}$, Sanjib Koirala ${ }^{3}$, Ram Kumar Singh ${ }^{4}$
}

\begin{abstract}
Affiliation
1. Lecturer, Department of Surgery, Birat Medical College Teaching Hospital, Nepal

2. Medical Officer, Birat Medical College Teaching Hospital, Nepal

3. Research Mentee, NMVSResearch Academy, Morang, Nepal

4. Professor, Department of Surgery, Birat Medical College Teaching Hospital, Nepal
\end{abstract}

\section{ARTICLE INFO}

\section{Received : 11 August, 2021}

Accepted : 21 January, 2022

Published : 22 January, 2022

(c) Authors retain copyright and grant the journal right of first publication with the work simultaneously licensed under Creative Commons Attribution License CC - BY 4.0 that allows others to share the work with an acknowledgment of the work's authorship and initial publication in this journal.

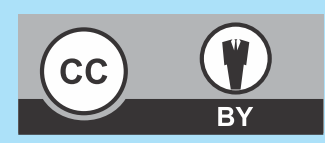

ORA 278

DOI: https://doi.org/10.3126/bjhs.v6i3.43203

\section{* Corresponding Author}

Dr. Sanjaya Kumar Yadav Lecturer

Department of Surgery

Birat Medical College Teaching Hospital, Nepal

Email: bsanzayadav@gmail.com

ORCID: https://orcid.org/0000-0002-4052-6475

\section{Citation}

Comparative study of laparoscopic appendectomy versus open appendectomy at Birat Medical College Teaching Hospital. Sanjaya Kumar Yadav, Sabin Shrestha, Sanjib Koirala, Ram Kumar Singh. BJHS 2021;6(3)16.1611-1614.

\section{ABSTRACT}

\section{Introduction}

Appendicitis is a commonly encountered surgical problem. Both laparoscopic appendectomy and open appendectomy are common ways of surgical intervention

\section{Objective}

The objective of this study was to find the outcome of laparoscopic appendectomy versus open appendectomy in terms of duration of surgery, length of hospital stay, pain, and wound infection at Birat Medical College Teaching Hospital.

\section{Methodology}

A hospital-based comparative cross-sectional study was conducted from 1 February 2021 to 30 July 2021 among 60 appendicitis patients at the surgery department of Birat Medical College Teaching Hospital. Ethical clearance was taken from the institutional review committee (Ref: IRC-PA098/2077-78 ) of Birat Medical College Teaching Hospital and informed written consent was taken from each study participant. Collected data were entered in Microsoft Excel and analyzed by SPSS 23 . Frequency, mean and standard deviation were used for univariate analysis. Independent sample t-test and chi-square test were used for bivariate analysis and statistical significance was set at $95 \%$ confidence interval and $p$-value less than 0.05 .

\section{Result}

The mean age of the open appendectomy group was $30 \pm 16.85$ years and the laparoscopic appendectomy group was $33.47 \pm 13.29$ years. The majority were female 32 (53.3\%). The mean duration of surgery $(p=0.003)$ and length of hospital stay $(p=0.001)$ was found to be statistically significant between the two groups. The post-operative pain score at 6 hours, 12 hours and 24 hours has no statistically significant difference between both groups. Further, no statistically significant difference was found for wound infection ( $p=0.053)$.

\section{Conclusion}

In our centre, despite having more duration of surgery for laparoscopic appendectomy, the length of hospital stay is less. Postoperative pain score at different times and wound infection has no difference. Surgeons need to be more informed in both ways of surgeries for its outcome because of no clear-cut better outcomes in either method.

\section{KEYWORDS}

Appendicitis, laparoscopic appendectomy, open appendectomy, outcomes 


\section{INTRODUCTION}

Appendicitis is a commonly encountered surgical problem. The two modalities of appendectomy are evident. Laparoscopic appendectomy is a new technique than open appendectomy. Both laparoscopic appendectomy and open appendectomy are practised in different surgical settings. ${ }^{1}$ The outcome of appendectomy matters whether it is an open appendectomy or laparoscopic appendectomy. The outcome in terms of duration of surgery, length of hospital stay, pain, and wound infection reported by various studies in different settings was different. ${ }^{2-6} A$ study found the postoperative pain and hospital stay were less in laparoscopic appendectomy than open appendectomy. ${ }^{2}$ Another study found postoperative pain score at different time was less in the laparoscopic appendectomy group than the open appendectomy group. ${ }^{3}$ The outcome in terms of duration of surgery, length of hospital stay, pain, wound infection is not accessed in our centre. We found this as a research gap and conducted a study with an objective to find the outcome of laparoscopic appendectomy versus open appendectomy in terms of duration of surgery, length of hospital stay, pain, and wound infection at Birat Medical College Teaching Hospital.

\section{METHODOLOGY}

A hospital-based comparative cross-sectional study was conducted from 1 February 2021 to 30 July 2021 among 60 appendicitis patients at the surgery department of Birat Medical College Teaching Hospital. Ethical clearance was taken from the institutional review committee (Ref: IRC-PA098/2077-78 ) of Birat Medical College Teaching Hospital and informed written consent was taken from each study participant. A previous study conducted by Kumar GS reported standard deviation $(s 1=0.30)$ and $(s 2=0.40)$ in open and laparoscopic appendectomy groups respectively. ${ }^{7}$ Sample size was calculated by using a formula for two independent samples for the continuous outcome. By considering effect size (0.2), the sample size was; $n=2$ (Z*SDtotal/Effect Size) 2 where SD total $=\sqrt{\frac{\left(n_{1}-1\right) s_{1}^{2}+\left(n_{2}-1\right) s_{2}^{2}}{\left(n_{1}+n_{2}-2\right)}}$ and effect size $=($ Mean1-Mean2) $/$ SDtotal. So, the total number of patients in each group was 24 . Adjusting the $10 \%$ nonresponse rate, the minimum sample size was $24 / 0.9=27$, but we enrolled 30 patients in each group. The first patient was enrolled by the coin toss method and then each alternative patient was enrolled in each group after taking informed consent. Postoperative pain was assessed according to a visual analogue scale (VAS) from 0 (no pain) to 10 (worst pain imaginable). We assessed postoperative pain at 6 hours, 12 hours and 24 hours. The local wound infection was assessed on the 7th postoperative day. Collected data were entered in Microsoft Excel and doubled checked and analyzed by statistical package for social sciences (SPSS 23). Anonymity and confidentiality data was maintained. Frequency, mean and standard deviation were used for univariate analysis. Independent sample t-test and chi-square test were used for bivariate analysis and statistical significance was set at $95 \%$ confidence interval and $p$-value less than 0.05 .

\section{RESULTS}

We enrolled 30 patients in the open appendectomy group and 30 patients in the laparoscopic appendectomy group. The mean age of the open appendectomy group was $30 \pm 16.85$ years and the laparoscopic appendectomy group was $33.47 \pm 13.29$ years. The majority were female 32 (53.3\%) (Table 1).

\begin{tabular}{|c|c|c|c|}
\hline \multicolumn{2}{|c|}{ Age (Mean \pm SD) years } & \multicolumn{2}{|c|}{ Sex } \\
\hline Open & Lap & Male & Female \\
\hline $30 \pm 16.85$ & $33.47 \pm 13.29$ & $28(46.7 \%)$ & $32(53$ \\
\hline
\end{tabular}

Duration of surgery matters for postoperative outcomes. The mean duration of surgery was more in the laparoscopic appendectomy group $(43.67 \pm 6.94)$ than the open appendectomy group (35.83 \pm 12.11$)$, which was found to be statistically significant $(p=0.003$ ) (table 2 ).

\begin{tabular}{|c|c|c|c|}
\hline $\begin{array}{l}\text { Open Appendectomy } \\
(n=30)\end{array}$ & $\begin{array}{c}\text { Laparoscopic } \\
\text { Appendectomy }(n=30)\end{array}$ & t-test & p-value \\
\hline $35.83 \pm 12.11$ & $43.67 \pm 6.94$ & -3.074 & 0.003 \\
\hline
\end{tabular}

Length of hospital stay is important in any surgical procedure for its quality outcome. Regarding the length of hospital stay, it was more in the open appendectomy group $(3.93 \pm 1.26)$ than the laparoscopic appendectomy group $(1.7 \pm 0.65)$, which was found to be statistically significant $(p=0.001)$ (table 3).

\begin{tabular}{|c|c|c|c|}
\hline $\begin{array}{l}\text { Open Appendectomy } \\
(n=30)\end{array}$ & $\begin{array}{l}\text { Laparoscopic } \\
\text { Appendectomy } \\
(n=30)\end{array}$ & t-test & p-value \\
\hline $3.93 \pm 1.26$ & $1.7 \pm 0.65$ & 8.64 & 0.001 \\
\hline
\end{tabular}

Postoperative pain is an important parameter to assess for the quality of life of the patient. The postoperative pain after surgery varies as per procedure and time passes. At 6 hours, the postoperative pain score was more in the open appendectomy group $(5.07 \pm 0.79)$ than the laparoscopic appendectomy group $(4.77 \pm 0.68)$, which was not statistically significant $(p=012)$. At 12 hours, the postoperative pain score was more in the open appendectomy group $(3.13 \pm 0.82)$ than the laparoscopic appendectomy group (2.77 \pm 0.82$)$, which was not statistically significant $(p=0.09)$. At 24 hours, the post-operative pain score in both groups is similar and has no statistically significant difference was found (Table 4).

Table 4. Comparison of postoperative pain score at different times $(n=60)$

\begin{tabular}{|c|c|c|c|c|}
\hline $\begin{array}{l}\text { Post Operative } \\
\text { Pain Score }\end{array}$ & $\begin{array}{l}\text { Open Appendectomy } \\
(n=30)\end{array}$ & $\begin{array}{l}\text { Laparoscopic } \\
\text { Appendectomy } \\
(n=30)\end{array}$ & t-test & p-value \\
\hline 6 hours & $5.07 \pm 0.79$ & $4.77 \pm 0.68$ & 1.58 & 0.12 \\
\hline 12 hours & $3.13 \pm 0.82$ & $2.77 \pm 0.82$ & 1.74 & 0.09 \\
\hline 24 hours & $1.9 \pm 0.8$ & $1.9 \pm 0.71$ & 0 & 1 \\
\hline
\end{tabular}


Wound infection is a major factor in the quality of surgical care. There was no statistically significant association between the open appendectomy and laparoscopic appendectomy in terms of wound infection $(p=0.053)$ (table 5). In terms of wound infection, both procedures has no pros and cons.

\begin{tabular}{|c|c|c|c|c|}
\hline \multicolumn{5}{|c|}{ Infection } \\
\hline & No & Yes & OR & P-value \\
\hline Open & $21(70 \%)$ & $9(30 \%)$ & 3.75 & 0.053 \\
\hline Lap & $27(90 \%)$ & $3(10 \%)$ & & \\
\hline
\end{tabular}

\section{DISCUSSION}

Surgical procedures are common at tertiary hospitals. They are either minor or major operations. People are always concerned about the quality of life during and after surgery. In our centre, many cases presented with appendicitis each day at the surgery department. Surgeons are familiar with both open appendectomy and laparoscopic appendectomy. The decision for open appendectomy versus laparoscopic appendectomy depends on the client choice and the surgical condition. The availability of instruments and skilled surgeons also differs in the choice of surgery. The outcome of both methods in terms of duration of surgery, length of hospital stay, postoperative pain, wound infection matters for both patients and the operating surgeons. Surgeons are always aware of this fact and patients are always curious about their outcomes. Both laparoscopic appendectomy and open appendectomy are commonly practised in tertiary care centres.

The outcome in terms of duration of surgery, length of hospital stay, pain, wound infection reported by various studies in different settings was different. ${ }^{2-6}$

We found the mean age of the open appendectomy group was $30 \pm 16.85$ years and the laparoscopic appendectomy group was $33.47 \pm 13.29$ years. Almost similar mean age in both groups was reported in another study. ${ }^{2}$ We found the majority were female $32(53.3 \%)$ which was similar to the study conducted in central Nepal. ${ }^{2}$ But in another study, males had higher rates of appendicitis than females. ${ }^{3-4}$

We found the mean duration of surgery was more in the laparoscopic appendectomy group $(43.67 \pm 6.94)$ than the open appendectomy group $(35.83 \pm 12.11)$, which was found to be statistically significant $(p=0.003)$. Similar findings were reported by another study from India. ${ }^{7}$ Similar findings were reported by another study where the mean operative time in laparoscopic appendectomy was 61.52 minutes and in open appendectomy 39.61 minutes $(p<0.001) .{ }^{10}$ Here open appendectomy seems better but we need to consider various factors to determine the outcome of surgery by a different procedure. But another study found similar operating times for both groups $(p=0.855) .{ }^{11}$ A metaanalysis found the duration of surgery was 10 minutes $(\mathrm{Cl} 6$ to 15$)$ longer for laparoscopic appendectomy. ${ }^{12}$ Another study also reported similar findings where laparoscopic appendectomy operating time was significantly greater than that of open appendectomy. ${ }^{13}$ In contrast to the above findings, the mean operative time was 55 minutes for the laparoscopic appendectomy group and 70 minutes for the open appendectomy group $(p<0.001) .{ }^{14}$

We found the length of hospital stay, was more in the open appendectomy group $(3.93 \pm 1.26)$ than the laparoscopic appendectomy group $(1.7 \pm 0.65)$, which was found to be statistically significant $(p=0.001)$. Similar findings were reported from another study where hospital stay was less in laparoscopic appendectomy. ${ }^{2}$ The length of hospital stay was significantly more in the open appendectomy group than in the laparoscopic appendectomy group. ' Similar findings were reported from another study where the mean length of hospital stay in laparoscopic appendectomy was 2.69 days and in open appendectomy 4.03 days $(p<0.001) .{ }^{10}$ In addition, a significant difference was found between the two modalities in terms of the length of hospital stay. ${ }^{13}$ Mean hospital stay was 5 days and 6 days for laparoscopic appendectomy and open appendectomy groups respectively $(p<0.001){ }^{14}$ So, in almost all studies reported hospital stay is more in open appendectomy group than laparoscopic appendectomy group.

We found the postoperative pain score was more in the open appendectomy group $(5.07 \pm 0.79)$ than the laparoscopic appendectomy group $(4.77 \pm 0.68)$ at 6 hours, which was not statistically significant $(p=012)$. At 12 hours, the post-operative pain score was more in the open appendectomy group $(3.13 \pm 0.82)$ than the laparoscopic appendectomy group $(2.77 \pm 0.82)$, which was not statistically significant $(p=0.09)$. At 24 hours, the postoperative pain score in both groups is similar and has no statistically significant difference. The postoperative pain score at different times was less in the laparoscopic appendectomy group than the open appendectomy. ${ }^{3}$ There are many other factors that determine the perception of pain at the postoperative stage. A study conducted in Dhulikhel, Nepal reported a significant high pain score in the open appendectomy group than the laparoscopic appendectomy group. ${ }^{2}$ Significant high pain scores were found in the open appendectomy group (Mean \pm SD: $2.5 \pm$ 0.3 ) than laparoscopic appendectomy group (Mean \pm SD: 1.4 $\pm 0.4){ }^{7}$ The visual analogue scale scores of 1 st $(p=0.001)$, 6 th $(p=0.001)$ and 12 th $(p=0.028)$ hours were higher in open the appendectomy group. ${ }^{11}$

Wound infection determines the quality of surgical care during and after surgery. In our study, we found no statistically significant association between open appendectomy and laparoscopic appendectomy in terms of wound infection $(p=0.053)$. But a significant wound infection was reported in a study where open appendectomy has more would complications than laparoscopic appendectomy. ${ }^{7}$ Wound infections were less likely after the laparoscopic appendectomy group than after the open appendectomy group (OR 0.43; $\mathrm{Cl} 0.34$ to 0.54$).{ }^{13}$ Laparoscopic appendectomyfavor less wound infection. A meta-analysis recommended that using laparoscopy appendectomy in patients with suspected appendicitis unless laparoscopy 
itself is contraindicated or not feasible. Especially young female, obese, and employed patients seem to benefit from a laparoscopic appendectomy. ${ }^{12}$ Another research suggested that laparoscopic appendectomy is more useful for treating acute appendicitis, especially when perforated appendicitis is suspected. ${ }^{13}$

This type of research work will help the surgeons with rational thinking while following a type of surgical procedure. Evidence-based practice with rationale thinking would help patients for better compliance hence better service utilization. The cost of treatment also matters for the choice of surgical procedure. Choosing a surgical procedure might be not as easy as we think. We need to consider different medical, social, financial and cultural barriers.

\section{CONCLUSION}

In our Centre, despite having more duration of surgery for laparoscopic appendectomy, the length of hospital stay is less. Postoperative pain score at a different time and wound infection have no difference in both groups of appendectomy.

\section{RECOMMENDATIONS}

As long hospital stay is a major contributor to patient satisfaction, we recommend laparoscopic appendectomy as it has less length of hospital stay in comparison to open appendectomy. It would be better to have a meta-analysis of such a comparison from studies conducted in Nepal. We will further recommend conducting this study with a large number of samples from different centre with consideration of all factors that might affect the outcome of surgical techniques. Operational research in terms of the new procedure and its further outcome needs to be raised. The local information regarding the outcome of different medical care and practices needs to be generated as much as possible.

\section{LIMITATION OF THE STUDY}

While deciding and recommending open appendectomy versus laparoscopic appendectomy, various factors need to be considered. The patient's surgical condition, the skill of the doctor, availability of instruments, cost of surgery, willingness of the patient etc. are the other contributors.

\section{ACKNOWLEDGMENTS}

We would like to acknowledge our study participants, nursing professionals and supporting staff. We take this opportunity to thank and acknowledge the institutional review committee (IRC) of Birat Medical College Teaching Hospital.

\section{CONFLICT OF INTEREST}

We have no conflict of interest to declare for this research work.

\section{FINANCIAL DISCLOSURE}

We disclose no financial support for this research work.

\section{REFERENCES}

1. Appendectomy [Internet]. www.hopkinsmedicine.org. [cited 2021 Sep 12]. Available from: https://www.hopkinsmedicine.org/ health/treatment-tests-and-therapies/appendectomy.

2. Pradhan S, Shakya YR, Batajoo H, Malla B, Joshi HN, Thapa LB, et al. Laparoscopic versus open appendectomy: a prospective comparative study. Journal of Society of Surgeons of Nepal. 2015;18 (2):29-32. DOI: https://doi.org/10.3126/jssn.v18i2.18572

3. Mohammuddunnobi, Jahan T, Al Amin A. Comparison of laparoscopic appendectomy versus open appendectomy in acute appendicitis in obese diabetic patients. BIRDEM Medical Journal. 2020 Aug 23;10 (3):145-8. DOI: https://doi.org/10.3329/ birdem. v10i3.48701

4. Kumar S, Jalan A, Patowary BN, Shrestha S. Laparoscopic Appendectomy Versus Open Appendectomy for Acute Appendicitis: A Prospective Comparative Study. Kathmandu University medical journal [Internet]. 2016 Jul [cited 2021 Sep 12];14(55). Available from: https://pubmed.ncbi.nlm.nih.gov/28814687/ PMID: 28814687

5. Goudar BV, Telkar S, Lamani YP, Shirbur SN, Shailesh ME. Laparoscopic versus Open Appendectomy: A Comparison of Primary Outcome Studies from Southern India. Journal of Clinical and Diagnostic Research [Internet]. 2021 Dec 25 [cited 2021 Sep 12];15(9). Available from: https://www.jcdr.net/articles/ PDF/1772/27_3572_nit(f)(ky).pdf.

6. Singh LM, Wadiwa YS. A retrospective comparative study between laparoscopic and open appendectomy in teaching hospital of India. International Surgery Journal. 2018 Aug 25;5(9):3034-7. DOI: http://dx.doi.org/10.18203/2349-2902.isj20183718

7. Siva Kumar G, NagenderRao D. Open VS laparoscopic appendicectomy: A comparative study. International Journal of Surgery Science. 2018;2(2):19-22.
8. Lin K-B, Lai KR, Yang N-P, Chan C-L, Liu Y-H, Pan R-H, et al. Epidemiology and socioeconomic features of appendicitis in Taiwan: a 12-year population-based study. World Journal of Emergency Surgery. 2015 Sep 17;10(1):1-13.doi: 10.1186/s13017-015-0036-3

9. D J Humes JS. Acute appendicitis.British Medical Journal. 2006 Sep 9;333(7567):530. DOI: 10.1136/bmj.38940.664363.AE

10. Batajoo $\mathrm{H}$, Hazra NK. Laparoscopic versus open appendectomy in acute appendicitis. Journal of Nepal Health Research Council [Internet]. 2012 Sep [cited 2021 Sep 12];10(22). Available from: https://www.ncbi.nlm.nih.gov/pubmed/23281459. PMID: 23281459

11. Cipe G, Idiz O, Hasbahceci M, Bozkurt S, Kadioglu H, Coskun H, et al. Laparoscopic versus open appendectomy: where are we now? Chirurgia [Internet]. 2014 [cited 2021 Sep 12];109(4). Available from: https://www.ncbi.nlm.nih.gov/pubmed/25149616. PMID: 25149616

12. Sauerland S, Jaschinski T, Neugebauer EA. Laparoscopic versus open surgery for suspected appendicitis. Cochrane Database Systematic Reviews [Internet]. 2010 Oct 6 [cited 2021 Sep 12];(10). Available from: https://www.ncbi.nlm.nih.gov/pubmed/20927725. doi: 10.1002/14651858.CD001546.pub3. appendectomy useful for the treatment of acute appendicitis in Korea? A meta-analysis. Yonsei Medical Journal [Internet]. 2004 Feb 29 [cited 2021 Sep 12];45(1). Available from: https://pubmed.ncbi. nlm.nih. gov/15004862. DOI: 10.3349/ymj.2004.45.1.7

14. Yau KK, Siu WT, Tang CN, Yang GP, Li MK. Laparoscopic versus open appendectomy for complicated appendicitis. Journal of the American College of Surgeons [Internet]. 2007 Jul [cited 2021 Sep 12];205(1). Available from:
13. Kim CB, Kim MS, Hong JH, Lee HY, Yu SH. Is laparoscopic 